\title{
Awareness of professional ethics in midwifery
}

\author{
Shaghayegh Majzobi ${ }^{1}$, Hana Sohrabi ${ }^{* *}$, Ronak Shahoei ${ }^{3}$, Mahsa Sohrabi ${ }^{4}$ \\ 1- Midwifery Student, Student Research Committee, Kurdistan University of Medical Sciences, Sanandaj, \\ Iran. \\ 2- Midwifery Student, Student Research Committee, Kurdistan University of Medical Sciences, Sanandaj, \\ Iran.(Corresponding Author), Tel: +989301433949. \\ Email: honeyhana96@gmail.com \\ 3- Associate Professor, Department of Midwifery, School of Nursing and Midwifery, Kurdistan University \\ of Medical Sciences, Sanandaj, Iran. \\ 4-BSc in Nursing, Tohid Hospital, Kurdistan University of Medical Sciences, Sanandaj, Iran.
}

Received: 6 Jun 2018

Accepted: 3 Sep 2018

\section{Abstract}

Background \& Aim: Professional ethics is defined as ethical commitment and conscience in regards to every profession, duty or responsibility in order to prevent patient harm, which in turn accelerates recovery. The present study aimed to determine the level of knowledge regarding professional ethics and its influential factors among midwives in Sanandaj, Iran in 2017.

Materials and Methods: This cross-sectional study was conducted on 150 midwives employed in the hospitals and health centers in Sanandaj city. The subjects were selected via simple random sampling. Data were collected using a two-part questionnaire. The first section consisted of demographic characteristics, and the second section contained data on the knowledge of various aspects of professional ethics. Data analysis was performed in SPSS version 18 using descriptive and inferential statistics at the P-value of less than 0.05 .

Results: The general knowledge of the majority of the midwives (92\%) regarding professional ethics was favorable. In addition, significant associations were observed between marital status $(\mathrm{P}=0.046)$, workplace $(\mathrm{P}=0.010)$, and interest and motivation $(\mathrm{P}=0.013)$ with the general knowledge of professional ethics.

Conclusion: According to the results, the midwives employed in the hospitals and health centers in Sanandaj had proper knowledge of professional ethics.

Keywords: Professional Ethics, Midwife, Knowledge

How to cite this article:

Majzobi S, Sohrabi H, Shahoei R, Sohrabi M. Awareness of professional ethics in midwifery. Scientific Journal of Nursing, Midwifery and Paramedical Faculty. 2018; 3 (4) :58-66

URL: http://sinmp.muk.ac.ir/article-1-142-fa.html

Copyright () 2018 the Author (s). Published by Kurdistan University of Medical Sciences. This is an open access article distributed under the terms of the Creative Commons Attribution-Non Commercial License 4.0 (CCBY-NC), where it is permissible to download, share, remix, transform, and buildup the work provided it is properly cited. The work cannot be used commercially without permission from the journal. 


\title{
بررسى ميزان آكاهى ماماها از اصول اخلاق حرفهاى
}

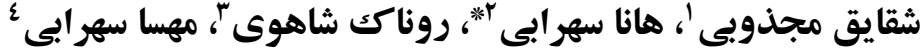

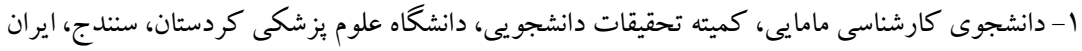

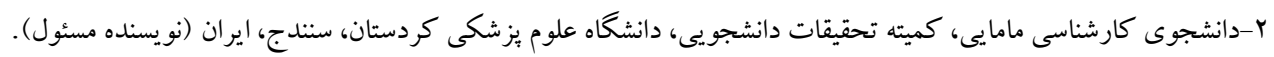 \\ تلفن: honeyhana96@gmail.com

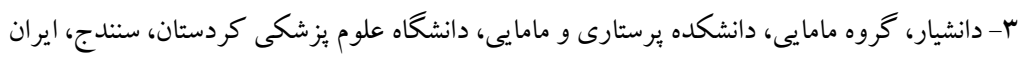



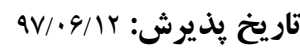

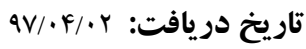

جكيده زمينه و هدف: اخلاق حرفهاى نوعى تعهد اخلاقى و وجدان كارى نسبت به هر نوع كار، وظيفه يا مسئوليت است به طورى




مواد و روشها: اين مطالعه مقطعى روى •ها نفر از ماماهاى شاغل در مراكز بهداشتى و بيمارستانى شهر ستندج انجام شد.



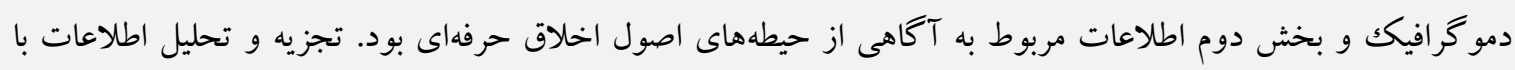

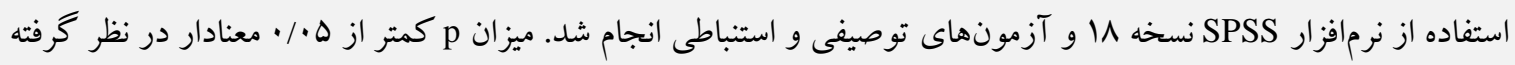

يافتهها: نتايج بثوهش نشان داد ميزان آكاهى كلى اكثريت ماماها (بوه/) از اصول اخلاق حرفهاى در حد خوب بود. از بين

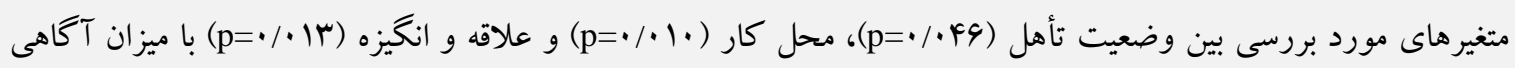
كلى ارتباط معنادار وجود داشت.

نتيجه كيرى: نتايج اين مطالعه نشان داد كه ماماهاى شاغل در مراكز بهداشتى درمانى و بيمارستانى شهر سنندج از نظر

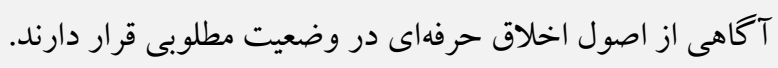
وازههاى كليدى: اخلاق حرفهاى، ماما، آكاهى

در واقع موضوع اخلاق تشخيص خوب از بد است

(Y). اخلاق حرفهاى نوعى تعهد اخلاقى و وجدان

مقدمه

كارى نسبت به هر نوع كار، وظيفه يا مسئوليت است اخلاق مجموعهاى از صفات روحى و باطنى

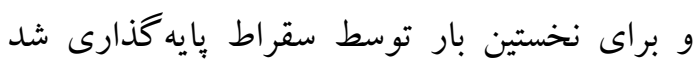
انسان است كه به صورت اعمال و رفتارى كه از خلقيات درونى انسان ناشى مىشود بروز مى كند (1). 
خدمات نمايد (•)؛؛ كه اغلب تبعات ناخوشايندى را

$$
\text { در بي خواهد داشت (11). }
$$

با بيشرفتهاى روزافزون اطلاعات و فنّاورى

يزشكى، مشكلات اخلاقى همراه آن هم روبه

افزايش است و راهنماهاى اخلاقى لازم است تا با

كاستن از اين مشكلات از سلامت انسانها حفاظت

كند. اين امر به خصوص در حرفه مامايى ضرورى به نظر مىرسد جر اكه ماما در حرفه خود همزمان با دو انسان سروكار دارد كه هركدام داراى حقوق مشخص هستند (Y)). هر حرفهاى، كدهاى اخلاقى را براى خود طراحى و اجرا مى كند و در نتيجه رعايت آنها، علاوه بر افزايش كيفيت مراقبتها و افزايش اعتماد عمومى به حرفه، به عنوان وسيلهاى براى رسيدن به عملكرد مطلوبتر استفاده خواهند شد (N). آشنايى شاغلين هر حرفه با قوانين حاكم بر آن حرفه مىتواند از بروز خطاها جلو گيرى نموده و به حفظ كيفيت خدمات آن حرفه كمك نمايد (IT)؛ بنابراين لازم است ماماها در ارائه خدمات و

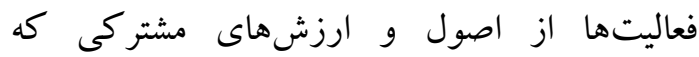
نمايانگر تعهد آنان به جامعه است بهره گيرند و با با رعايت آن، علاوه بر افزايش كيفيت مراقبت و افزايش اعتماد عمومى، به عنوان وسيلهاى براى رسيدن به عملكرد استاندارد و مطلوب استفاده نمايند (4). ماما به عنوان اولين فرد در تماس با مادر و نوزاد در مراكز بهداشتى و درمانى، علاوه بر توانايى تشخيص زودرس باردارى و زايمان برخطر، بايد قادر به تصميم گيرى در مواقع اورزانس بوده و در زمان بروز فوريتها با دانش و مهارت كافى اقدامات

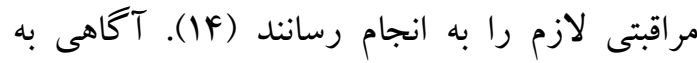

(r). شايستگى اخلاق حرفهاى را مىتوان معادل شايستخى حرفهاى دانست (Y). هرقدر رعايت اخلاق حرفهاى فراكيرتر باشد، ميزان تعهد به اصول آن نيز افزايش مىيابد و هرقدر محدوديتهاى اعمال شده ناشى از اصول اخلاق حرفهاى منطقىتر و در رشد سازمان مؤثرتر باشد، بايبندى به آن محكمتر خواهد بود (F). اخلاق حرفهاى باعث وجدان كارى نسبت به مددجو و سازمان بهداشتى درمانى مى گردد به طورى كه به مددجو آسيب نرساند و مراقبتها براى مددجو سير بهبودى به همر اه داشته باشد (ه). عملكرد اخلاقى يكى از مؤلفههاى اصلى مراقبت از مادر و جنين است (4). عدالت، نيكو كارى،

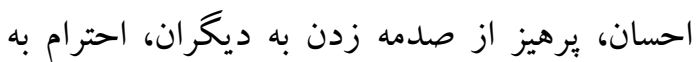
فرد، ايثار، رازدارى، كسب علم، معرفت نفس، ايمان، تقوا و تواضع از اصول و فضايل اخلاقى مهم در ارائه مراقبتهاى مامايى هستند كه ماماها موظف به رعايت آنها مىباشند (V). عملكرد منطبق با لـ اخلاق حرفهاى به نفع زنان و خانو ادههايشان، ماماها و حرفه مامايى است (^). رعايت اصول اخلاقى در حرفه مامايى مىتواند نقش اساسى در حمايت از مادران و مراجعين داشته باشد و ضامن حفظ حقوق بيماران است (9). از آن جايى كه آكاهى افراد تأثير

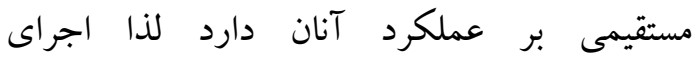
موفقيت آميز وظايف در گرو آكاهى كامل ماماها نسبت به قوانين و مقررات حرفهاى است. نآ كاهى از اين اصول گهُاه مىتواند منجر به صدمرات جبرانايذيرى براى مادر و جنين وى شود و و مشكلات و بيگردهاى قضايى را براى ارائه دهنده 
بود. معيارهاى ورود شامل حداقل 9 ماه سابقه كارى در حيطه مامايى و داشتن مدركك تحصيلى مامايى بود. حجم نمونه بر اساس مطالعات قبلى (Y I) و با در

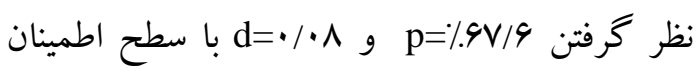
ه \% حجم نمونه برابر 4سا نفر برآورد شد كه به منظور افزايش دقت •ما نفر مورد بررسى قرار كرفتند. ابزار گردآورى اطلاعات شامل يرسشنامهاى دو قسمتى بود بخش اول حاوى اطلاعات جمعيت شناختى و بخش دوم اطلاعات مربوط به سنجش آكاهى از اصول اخلاق حرفهاى ماماها بود. اين ابزار مشتمل بر || سؤال در حيطه تعهدات حرفهاى، 11 سؤال در حيطه ارائه خدمات مامايى به مددجو و


خود، Vؤال در حيطه آموزش و ئزوهش و هائ سؤال در حيطه مديريت بود كه بر اساس كدهاى اخلاق حرفهاى مامايى در ايران توسط بزوهشخران تهيه شده بود. ياسخها به صورت كاملاً مخالفم ( امتياز) تا كاملاً موافقم (ه امتياز) جيده شدهاند. براى تعيين اعتبار علمى بيرسشنامه از روش روايى محتوا استفاده شد كه بدين منظور از نظرات ·ـ الفر از اعضاى

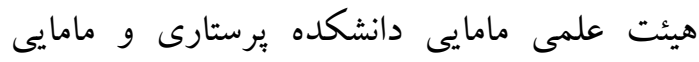
استفاده گرديد و اصلاحات لازم به عمل آمد. يايايى ليى "يرسشنامه با استفاده از ضريب آلفاى كرونباخ AF/ • به دست آمد. كسب نمره كلى كمتر از سل به منزله آكاهى ضعيف، نمره VF-IFV به منزله آكاهى متوسط و نمره •YYM-YY ا به منزله آكاهى خوب بود. در حيطه تعهدات حرفهاى و ارائه خدمات مامايى به مددجو و همراهان وى نمره كمتر از 19 نشان دهنده

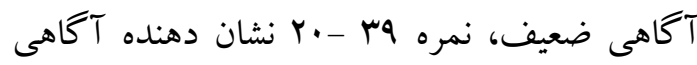

قوانين و مقررات موازين فنى و علمى و ارتباط مناسب با بيماران مىتواند در كاهش شكايت مؤثر واقع شود (ها). كسانى كه تازه وارد حرفه مامايى مىشوند بايستى از ملاحظات اخلاقى كه ممكن است در هر شيفت براى آنها بيش آيد مطلع باشند

مطالعه يوسف زاده و همكاران در رابطه با تعيين آكاهى و نكرش و عملكرد ماماهاى شاغل در زايشگاه بيمارستانهاى آموزشى مشهد نشان داد،



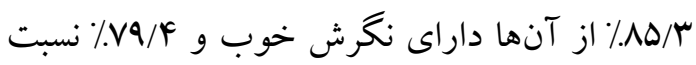
به كدهاى اخلاق حرفهاى عملكرد متوسط داشتند (9). مطالعات مختلف ميزان آكاهى ماماهاى شاغل در مراكز بهداشتى و بيمارستانى در شهرهاى مختلف ايران از اصول اخلاق حرفهاى را ارزيابى كرده است اما مطالعهاى در خصوص ميزان آكاهى ماماها از كدهاى اخلاق مامايى در شهر سنندج يافت نشد. با توجه به اينكه ميزان آكاهى ماماها به عنوان يكى از حرفهاى وابسته به يزشكى در حفظ سلامتى و بهبودى مادر و نوزاد از اهميت زيادى برخوردار است و همجنين مىتواند از ميزان خطاهاى حرفهاى جلو گيرى كند لذا اين مطالعه با هدف تعيين ميزان آكاهى از اصول اخلاق حرفهاى و عوامل مؤثر بر آن در ماماهاى شاغل شهر سنندج در سال وهبا انجام شلد.

\section{مواد و روشها}

اين مطالعه از نوع توصيفى تحليلى است. جامعه مورد مطالعه شامل كليه ماماهاى شاغل در مراكز

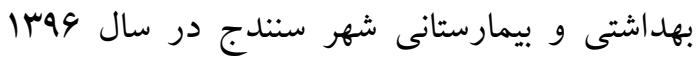


علوم يزشكى كردستان و با كسب رضايت شفاهى از شر كت كنند كان نمونه كيرى انجام شد. تجزيه و تحليل دادهها با نرمافزار SPSS نسخه 1/ ا و آزمونهاى ضريب همبستكى اسييرمن، آزمون كاى اسكوئر، من ويتنى و كروسكال واليس انجام شد.

\section{يافتهها}

نتايج حاصل از مطالعه نشان داد كه اكثريت افراد مورد مطالعه (TF/V\%) در محدوده سنى قرار داشتند و داراى تحصيلات كارشناسى بودند. ساير اطلاعات جمعيت شناختى در جدول ا ارائه
متوسط و نمره بيشتر از هس نشان دهنده آكاهى خوب بود. در حيطه ارتباط با همكاران وجود نمره كمتر از

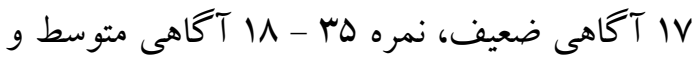
نمره بيشتر از ها آكاهى خوب را نشان مىداد. در حيطه آموزش و ئزوهش كسب نمره كمتر از


از DD Tكاهى خوب بود. در حيطه مديريت، نمره كمتر از 9 آكاهى ضعيف، نمره 19-1.1 آكاهى متوسط و نمره بيشتر از 19 آكاهى خوب بودي لهره

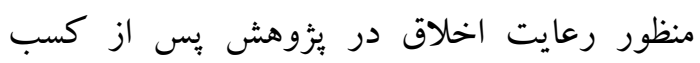
مجوز از معاونت يثزوهشى و كميته اخلاق دانشگاه

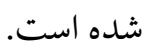

\begin{tabular}{|c|c|c|c|}
\hline \multicolumn{2}{|c|}{ فراوانى } & \multirow{2}{*}{\multicolumn{2}{|c|}{ متغير ها }} \\
\hline درصد & تعداد & & \\
\hline$r \cdot / v$ & kq & مجرد & \multirow{2}{*}{ 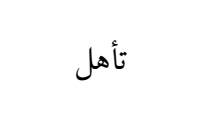 } \\
\hline $99 / \pi$ & 1.4 & متأهل & \\
\hline $1 \cdot / V$ & 19 & كمتر از 1 سال & \multirow{5}{*}{ سابقه كار } \\
\hline$r G / V$ & f. & ه-1 سال & \\
\hline$r M / r$ & rr & 9 تا · اسال & \\
\hline $10 / r$ & r & 1ا تا ها سال & \\
\hline Y9 & $r q$ & 19 سال و بالاتر & \\
\hline$F I / r$ & 94 & صبح كار ثابت & \multirow{2}{*}{ شيفت كارى } \\
\hline$\Delta \Lambda / V$ & $\Lambda$ & ساير & \\
\hline rr & FA & خيلى زياد & \multirow{4}{*}{ علاقه و انخيزه } \\
\hline Fr & $9 \pi$ & زياد & \\
\hline$r \mid / r$ & rr & متوسط & \\
\hline$F / V$ & $\mathrm{v}$ & كم علاقه و بى علاقه & \\
\hline 90 & $9 \mathrm{~V}$ & بلى & سابقه شر كت در \\
\hline ro & $\Delta r$ & خير & كار گاه اخلاق \\
\hline
\end{tabular}


هانا سمرابى

\begin{tabular}{|c|c|c|}
\hline rr & Fᄉ & واحدهاى درسى دانشگاه \\
\hline YA/V & Fr & مطالعه شخصى \\
\hline ir & 11 & آزمون ضمن خدمت \\
\hline$T V / r$ & FI & كار گاه \\
\hline
\end{tabular}

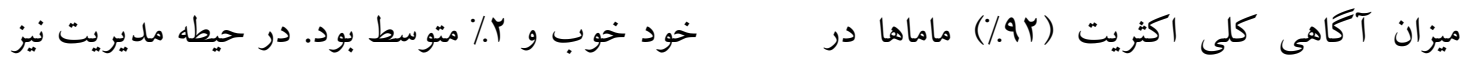



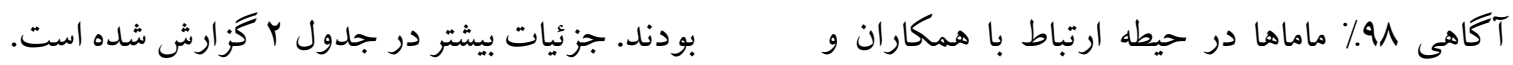

\begin{tabular}{|c|c|c|c|c|c|c|c|c|c|c|}
\hline \multicolumn{2}{|c|}{ مديريت } & \multicolumn{2}{|c|}{ خ ارتباط با همكاران و } & \multicolumn{2}{|c|}{ آموزش و يثوهش } & \multicolumn{2}{|c|}{ مدائه خدمات مامايى به } & \multicolumn{2}{|c|}{ تعهدات حرفهاى } & \multirow[t]{2}{*}{ ميزان آكاهى } \\
\hline درصد & تعداد & درصد & تعداد & درصد & تعداد & درصد & ت تعداد & درصد & تعداد & \\
\hline 9 & 9 & $r$ & $r$ & $r \cdot / V$ & m & re & $\Delta 1$ & $r \mu / r$ & ro & متوسط \\
\hline$q F$ & $|f|$ & $9 \wedge$ & IFV & $V 9 / \mu$ & 119 & 99 & 99 & $V 9 / V$ & 110 & خوب \\
\hline $1 \cdots$ & 10. & $1 \cdots$ & 10. & $1 \cdots$ & 10 & $1 \ldots$ & 10. & $1 \ldots$ & 10. & جمع \\
\hline
\end{tabular}

منبع كسب اطلاعات ( همجنين بين ميزان آكاهى كلى با متغيرهاى علاقه و

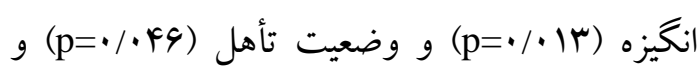

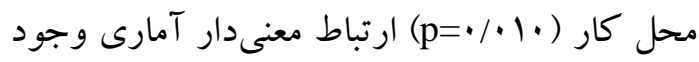

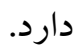

\section{بحث و نتيجه تيرى}

كدهاى اخلاق حرفهاى، راهنماى بسيار مهمى در ارائه اخلاقى خدمات در حرفه مامايى مىباشد كه تدوين آن بر اساس شرايط كارى و فرهنگى كشور در دفاتر مامايى وزارت بهداشت انجام شده است (9). در مطالعه حاضر در رابطه با اصول اخلاق حرفهاى، ميزان آكاهى بيشتر ماماها (Yr٪٪) در حد خوب و (^.^) در حد متوسط بود و هيج كدام از ماماها آكاهى ضعيف نداشتند. همجِنين بين متغير
در زمينه منابع كسب اطلاعات ماماهاى مورد يزوهش از اصول اخلاق حرفهاى، بيشترين منبع كسب اطلاعات واحدهاى درسى دانشگاه (rr.) و مطالعات شخصى (YN/V/) بود. نتايج يثروهش نشان داد ميزان آكاهى در حيطه ارائه خدمات مامايى به

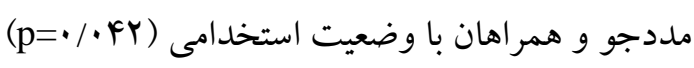
و سابقه شركت در سمينار و كاركاه اخلاق ارتباط دارد، همجنين ميزان آكاهى در (p=•/FF) حيطه آموزش و يزوهش با علاقه و انكيزه


اخلاق (·F/F) ارتباط داشت. ميزان آكاهى در حيطه ارتباط با همكاران و خود با سن (سب•/ (p)،

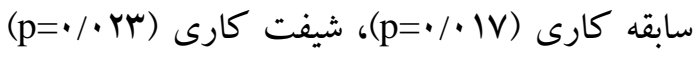
و وضعيت استخدامى (r) (p= ) ارتباط داشت. همجينين ارتباط ميزان آكاهى در حيطه مديريت با 


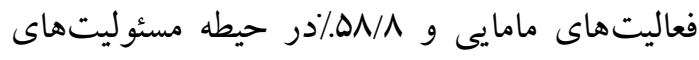
حرفهاى داراى آكاهى متوسطى بودند (9). نتايج اين مطالعه با مطالعه حاضر تقر يباً همخو انى داشت. دارئ از بين متغيرهاى مورد بررسى فقط بين وضعيت

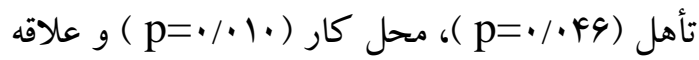


معنى دارى وجود داشت. در مطالعه جعفرى منش و همكاران بين وضعيت تأهل و علاقه به رشته با ميزان رعايت كدهاى اخلاق حرفهاى ارتباط معنادارى وجود داشت (19). در مطالعه معصومى و همكاران هم بين وضعيت تأهل با رعايت كدهاى اخلاق حرفهاى ارتباط آمارى معنادارى وجود داشت (9) كه نتايج اين دو مطالعه مشابه مطالعه حاضر بود. ممكن است دليل اين يافته را بتوان به احساس مسئوليت بيشتر افراد متأهل نسبت داد. يافتههاى ديخر يتر اين مطالعه نشان داد از بين متغيرهاى مورد بررسى، بين حيطه ارائه خدمات مامايى به مددجو و همراهان وى با وضعيت استخدامى و سابقه شر كت در سمينار و كار گاه اخلاق، بين حيطه آموزش و ويزوهش با علاقه و انخيزه و سابقه شركت در سمينار و كار گاه اخلاق، بين حيطه ارتباط با همكاران و خود با سن، سابقه كارى، شيفت كارى و وضعيت استخدامى و بين حيطه مديريت با منبع كسب اطلاعات ارتباط معنادار وجود داشت. نتايج حاصل از مطالعه رفيعى و همكاران نشان داد از بين متغيرهاى مورد بررسى بين حيطه اخلاقى-حرفهاى با وضعيت استخدامى و و بخش محل خدمت فرد، بين حيطه قانونى با سابقه كار و بين حيطه ارتباطى با بخش محل خدمت فرد
علاقه و انگيزه با ميزان آكاهى كلى ارتباط معنىدارى وجود داشت. در مطالعه شاهحسينى و همكاران كه بر روى •lf أنفر از ماماهاى شاغل در

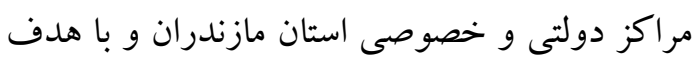
بررسى ميزان آكاهى ماماها از قوانين حقوقى و

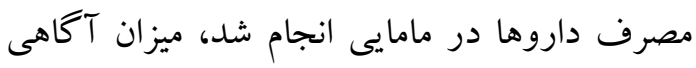

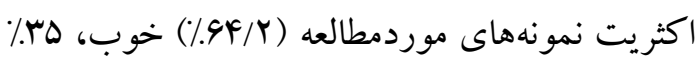
متوسط و •/N/\% ضعيف بود ( •).

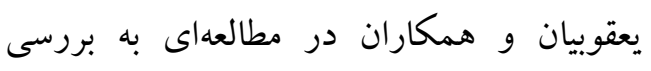
دانش برستاران در مورد مقررات حرفهاى برداختند.

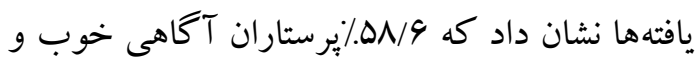
ץ/هั\% آكاهى متوسطى داشتند (IV). در مطالعه ديخرى كه در زنجان انجام شد، هV/V. يرستاران و ماماهاى بيمارستانهاى شهر زنجان در زمينه

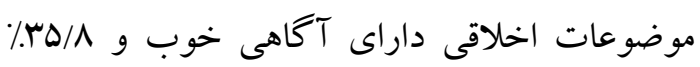
داراى آكاهى متوسط بودند (1) (1). اين يافتها ها با نتايج

$$
\text { ئزوهش حاضر قرابت دارد. }
$$

در يزٔوهش رفيعى و همكاران كه بر روى برستاران و ماماهاى شاغل در بيمارستانهاى شهر همدان با هدف بررسى ميزان آكاهى از اصول اخلاق حرفهاى انجام شد بيشترين آكاهى واحدها در حيطه اخلاقى -حرفهاى و ارتباطى بود (r)؛ كه با مطالعه حاضر همخوانى دارد. همجنين در مطالعه واثق رحيم يرور و همكاران نيز ماماهاى شاغل در مراكز بهداشتى درمانى تهران در حيطه ارتباط با همكاران

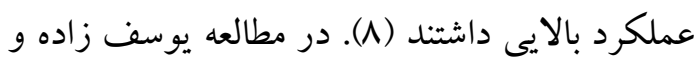
همكاران ميزان آكاهى ماماهاى شاغل در زايشگاه بيمارستانهاى آموزشى مشهد بررسى شد كه نمونهها در حيطه ارتباطات و ب1/1/1 در حيطه 


$$
\begin{aligned}
& \text { ارتباط معنادار وجود داشت (r) كه با مطالعه حاضر } \\
& \text { همخوانى نداشت. } \\
& \text { نتايج اين مطالعه نشان داد كه ماماهاى شاغل در } \\
& \text { مراكز بهداشتى درمانى و بيمارستانى شهر سنندج از } \\
& \text { نظر آكاهى از اصول اخلاق حرفهاى در وضعيت } \\
& \text { مطلوبى قرار دارند. از آن جايى كه علاوه بر آكاهى آنى } \\
& \text { ماماها، عملكرد آنان در رابطه با مسائل اخلاقى نقش } \\
& \text { بسيار مهمى در ارائه مراقبتهاى حرفهاى دارد لذا } \\
& \text { توصيه مىشود مطالعهاى ديخر در ارتباط با ميزان } \\
& \text { رعايت اصول اخلاق حرفهاى در ماماها انجام گيرد. }
\end{aligned}
$$$$
\text { تشكر و قدردانى }
$$$$
\text { اين يزوهش حاصل طرح تحقيقاتى مصوب }
$$

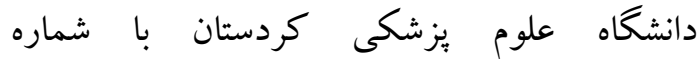$$
\text { |F/VD.99/F | است. بدينوسيله از حمايت }
$$$$
\text { معاونت محترم و شوراى محترم بثزوهشى دانشگاه }
$$$$
\text { علوم بزئى كردستان، ماماهاى شركت كننده در }
$$$$
\text { مطالعه و مسئولين بيمارستانها و درمانغاهها و كليه }
$$$$
\text { صميمانه قدردانى به عمل مى آيد. }
$$

\section{References}

1.Izadi A, Imani E, Khademi Z, Asadi Noughabi F, Haji Zadeh N, Naghi Zadeh F. The Correlation of Moral Sensitivity of Critical Care Nurses with their Caring Behavior. Iranian Journal of Medical Ethics and History of Medicine. 2013; 6(2): 43-56. [Persian].

2.Jahanpour F, Khalili A, Ravanipour M, Nourouzi L, Khalili M, Dehghan F. Investigating Awareness Amount of Nursing Students of Medical Sciences University of Bushehr about Ethic in Nursing Profession. Armaghane-Danesh,Yasuj University of Medical Sciences Journal. 2013; 19(3): 223-232. [Persian].

3.Rafiei M, Mohamadi N, Shobeiri F, Roshanaei G. Awareness Rate of Nurses and Midwives Working in the Hospitals of Hamadan on Principals of Professional Ethics. Pajouhan Scientific Journal. 2013; 13(1): 24-32. [Persian].

4.Sheikh Zakaryaie N, Atash Zadeh-Shoorideh F. The Relationship Between Professional Ethics and Organizational Commitment of Faculty Members in Kurdistan University of Medical Sciences. Journal of Shahid Beheshti; Nursing and Midwifery Faculty. 2015; 25(91): 21-30. [Persian].

5.Dehghani A, Dastpak M, Gharib A. Barriers Ti Respect Professional Ethics Standards in Clinical Care; Viewpoints of Nurses. Iranian Journal of Medical Education. 2013; 13(5): 421-430. [Persian].

6.Masumi Z, Golalizadeh Bibalan F, Roshanaei G. Observance of Midwifery Code of Ethics Among Midwifery Students and its Related Factors. Journal of Medical Ethics. 2016; 10(35): 11-30. [Persian].

7. Ahmari Tehran H, Abediny Z, Kachoie A, Jafar Begloo E, Tabibi M. The Effect of Integration of Role-Modeling and Narration Methods on the Midwifery Students Performance in Professional Ethics. Iranian Journal of Medical Education. 2012; 12(11): 826-835. [Persian].

8. Vasegh Rahim Parvar F, Nasiriani L, Faraj Khode T, Bahrani N. Compliance Rate of Midwifes with the Professional Code of Ethics in Maternal Child Health Center in Tehran. Iranian Journal of Medical Ethics and History of Medicine. 2014; 7(2): 36-46. [Persian]. 
9. Yousef Zadeh S, Kordi M, Mazlum R, Tara F. The Survey of Midwifes Knowledge,Attitude and Practice about Professional Ethics in the Maternity of Mashhad Educational Hospitals in 2014. Iranian Journal of Obstetrics Gynecology and Infertility. 2015; 18(173): 23-31. [Persian].

10.Shah Hoseini Z, Rashidi S, Abedian K. Midwives Awareness of Legal Rule and Drug Use in Midwifery. Journal of Forensic Medicine. 2005; 11(3): 132-135. [Persian].

11. Mohammadi F. Midwives Knowledge of Professional Rules and Its Relation with Some Factors in Qazvin. The Journal of Qazvin University of Medical Science. 2006; 10(2): 95-96. [Persian].

12. Baghani R, Framarzi F, Baghjary M, Zare F, Tabrayi Y. Assessment of Observance of Ethical Codes by Midwifery Students During Vaginal Examinations in Maternity Wards and Factors Affecting them. Journal of Mazandaran University of Medicalsciences. 2013; 23(107): 90-94. [Persian].

13. Mahjal Aghdam A, Ali Nezhad H, Abdoulah Zadeh F, Rahmani A, Samadi Rad B. Nurses Knowledge of Professional Rules in Educational Centers of Tabriz University of Medical Sciences. Journal of Nursing and Miwifery of Tabriz. 2011; 20: 26-32. [Persian]. 14.Kohan S, Mohammad Ali Beigi M, Taebi M. Midwive's Experiences of Applying Critical Thinking in High Risk Situations at Labor Unit. Iranian Journal of Medical Education. 2013; 13(3): 341-352. [Persian].

15. Faraj Khoda T, Latif Nezhad Roudsary R, Abasi M. Features of the Effective System Examining Ethical Professional Misconduct in Providing Reproductive Health Services. Journal of Medical Ethics. 2011;5(16): 133-162. [Persian].

16. Banian S, Sereshti M. The Survey of Knowledge of Midwives in Chaharmahal and Bakhtiari Province Regarding the Legal and Religious Rulings of Midwifery and Some Related Factors in 2006. Journal of Shahrekourd University of Medical Sciences. 2007; 9(3): 37-44. [Persian].

17. Yaghobian M, Yaghobi T, Salmeh F, Golmohammadi F, Safari R, Ghanei N, Habibi K. Comparing The Effect of Teaching Using Education Booklets and Lecture along with Education Booklet on Nurses' Knowledge about Professional Laws and Regulations. Iranian Jounal of Medical Education 2010; 9(4): 372-381. [Persian].

18. Negarandeh R, Ghobadi S. A Survey of Knowledge and Attitudes of Zanjan Hospitals Nurses and Midwives Towards Ethical Issues. Journal of Zanjan University of Medical Sciences 2001; 36(9): 55-59. [Persian].

19.Jafari Manesh H, Ranj Baran M, Vakilian K, Tajik R, Almasi-Hashiani A. Nursing's Code of Ethics:A Survey of Respecting the Code Among Nursing Students. Iranian Journal of Medical Ethics and History of Medicine. 2014; 6(6): 45-55. [Persian]. 